Meta

Journal des tradlucteurs

Translators' Journal

\title{
Daniel SLOATE et Denis G. GAUVIN (1985) : les Traquenards de la grammaire anglaise, Montréal, Guernica, 198 p.
}

\section{Robert Larose}

Volume 35, numéro 2, juin 1990

URI : https://id.erudit.org/iderudit/003409ar

DOI : https://doi.org/10.7202/003409ar

Aller au sommaire du numéro

Éditeur(s)

Les Presses de l'Université de Montréal

ISSN

0026-0452 (imprimé)

1492-1421 (numérique)

Découvrir la revue

Citer ce compte rendu

Larose, R. (1990). Compte rendu de [Daniel SLOATE et Denis G. GAUVIN (1985) : les Traquenards de la grammaire anglaise, Montréal, Guernica, 198 p.] Meta,

35(2), 441-442. https://doi.org/10.7202/003409ar d'utilisation que vous pouvez consulter en ligne.

https://apropos.erudit.org/fr/usagers/politique-dutilisation/ 
Daniel SLOATE et Denis G. GAUVIN (1985): les Traquenards de la grammaire anglaise, Montréal, Guernica, 198 p.

Comme il est indiqué dans l'avant-propos du livre, le but des auteurs n'est pas de proposer un traité de grammaire anglaise mais de «mettre en relief les notions essentielles sans lesquelles il est vain de penser acquérir l'assurance qu'exige la construction correcte de la phrase anglaise». Les Traquenards de la grammaire anglaise s'adresse à tous ceux qui ont déjà été initiés à l'anglais, et plus particulièrement aux étudiants en traduction.

Le livre est divisé en cinq chapitres (1. Le verbe: la conjugaison; 2 . Le nom et l'article; 3 . Adjectifs et pronoms divers; 4 . Le verbe: modes et temps; 5 . L'adverbe et 
les mots de liaison) suivis d'une liste des verbes irréguliers et d'un index alphabétique détaillé.

Les Traquenards de la grammaire anglaise est rédigé dans un français clair, sans ambages terminologiques. Chaque fois que les auteurs emploient une expression technique (p. ex. infinitif incomplet, p. 85), ils prennent soin d'en proposer une définition simple et succincte. Tout à fait appropriés au contexte canadien, les nombreux exemples bilingues rappellent à certains égards la présentation de la Grammaire de l'anglais contemporain de J. Draps ou du Manuel de l'angliciste de P. Rafroidi.

L'optique générale est nettement comparative comme en témoignent les nombreuses sous-sections intitulées «Traduction de...» ou les passages comme celui-ci:

L'âge : le Français dit : "Quel âge avez-vous?»; l'Anglais: * «Combien vieux êtes-vous?»

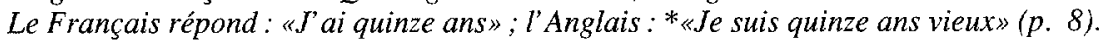

À noter que MM. Sloate et Gauvin se gardent de faire certaines déductions sur la psychologie des peuples, piège que certains comparatistes n'ont pas toujours su éviter.

Il faut féliciter les auteurs d'être parvenus à synthétiser (en 24 pages!) le système verbal de l'anglais et, pour chaque temps de verbe, d'avoir énuméré les possibilités de traduction d'anglais en français.

Il y aurait peut-être lieu qu'ils incorporent parmi leurs exemples un plus grand nombre de fautes commises fréquemment en thème au Canada français. (Nous songeons, entre autres, aux gallicismes.)

Les remarques portant sur le nombre et les règles d'accord des noms ainsi que sur les prépositions auraient pu être un peu plus détaillées. Par exemple, au sujet du pluriel anglais des noms d'animaux sauvages ou exotiques, a-t-on le choix d'écrire «a herd of

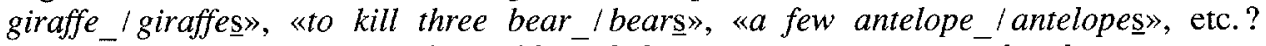
Qu'en est-il de l'accord de «three old English cannon_», «two counsel_who were never involved», «twenty aircraft_», etc. ? Est-ce qu'on dit «the United States is/are»?

Aussi faudrait-il rendre plus explicites les abréviations apparaissant dans les tableaux renfermant les diverses règles de grammaire (p. ex. à la p. 6, mieux vaudrait abréger «auxiliaire» par «aux.» plutôt que par «a»: adverbe? adjectif?). Une remarque semblable s'applique à l'emploi de la majuscule ou de la minuscule dans certains exemples: le Mont Carmel, le lac Huron, l'Océan Atlantique, la Reine Elizabeth II, l'empereur Napoléon (pp. 59-60).

Malgré ces quelques questions de détail, les Traquenards de la grammaire anglaise représente un excellent outil de référence qui pourrait certainement s'avérer utile dans les cours d'anglais langue seconde, ainsi que dans les cours de thème et de grammaire différentielle. Il ne reste plus maintenant qu'à demander aux auteurs: à quand le cahier d'exercices? 